\title{
Lay vs. Professional Perspectives: The Sexual and Reproductive Health of Orphans and Vulnerable Children in Uganda
}

\author{
Gloria K. Seruwagi \\ Department of Public Health, Victoria University, Kampala, Uganda \\ Email: gseruwagi@vu.ac.ug
}

Received 25 May 2014; revised 29 June 2014; accepted 20 July 2014

Copyright (C) 2014 by author and Scientific Research Publishing Inc.

This work is licensed under the Creative Commons Attribution International License (CC BY). http://creativecommons.org/licenses/by/4.0/

c. (i) Open Access

\begin{abstract}
Background/Introduction: Orphans and vulnerable children (OVC) in sub-Saharan Africa have been the focus of much popular and academic writing and the growing body of evidence cannot be overlooked. Existing research focuses on projections of OVC numbers, interventions, outcomes and descriptions of care arrangements. A lot of information exists on their poor sexual and reproductive health (SRH) status-most of it quantitative. The purpose of this paper is to present the voice and perceptions of OVC in regards to their SRH. Methods: This was a mixed-methods qualitative study drawing from phenomenology and it used purposive sampling to recruit 129 participants. Results: OVC perceptions and priorities do not always intersect with those of professionals and this has implications for existing and planned interventions. For example some OVC think favorably about early marriages while others have mechanisms of self-protection again SRH harm although this is not usually acknowledged. Conclusions: OVC demonstrate agency; therefore positioning them at the heart of service planning and delivery is an effective strategy in increasing the uptake and impact of interventions seeking to address their sexual and reproductive health needs.
\end{abstract}

\section{Keywords}

Orphans and Vulnerable Children, OVC, OVC Health, Child Health, Child Agency

\section{Introduction}

A growing body of research has emerged on the sexuality of orphans and vulnerable children (OVC) in subSaharan Africa and it presents a grim picture of their sexual and reproductive health. The evidence reports a heightened risk of HIV and sexual risk behaviours among adolescent orphans compared to their non-orphaned 
peers [1] [2]. The social, economic and psychological impacts of HIV/AIDS on OVC increase their vulnerability to HIV infection through early onset of sexual activity, commercial sex and sexual abuse [3] [4].

Uganda is one of the developing countries with a very high number of orphans and vulnerable children. The term "orphans and vulnerable children" (OVC) was developed following the limited usefulness of the tight definition of the construct orphanhood in the era of HIV/AIDS and encompasses children whose vulnerability is related to general aspects of their contexts such as poverty, abuse, disability, political repression and care by sick or elderly caregivers [5]. 57\% of Uganda's 30.7 million population are below 18 years of age and children below the age of 15 years comprise of more than half (50.7\%) of the total population [6] [7]. The percentage of orphaned children in Uganda increased from $11.5 \%$ in 1999 to $13.4 \%$ in 2003 and is currently at $14.8 \%$ [8]. An estimated 890,000 of all Ugandan orphans have lost their parents as a result of HIV/AIDS [9] [10] and this number increased to 2,500,000 in 2010 [8] [11]. Whereas up to 96\% of all children in Uganda have some level of vulnerability, it is $51 \%$ (totaling 8 million) who have been classified according to varying degrees of vulnerability. One out of every four households in Uganda has at least one orphan or vulnerable child [10] [11].

\subsection{Sexual Activity of OVC}

Social, economic and psychological impacts of HIV/AIDS on OVC increase their vulnerability to HIV infection through early onset of sexual activity, commercial sex and sexual abuse. Findings from earlier and recent studies in Uganda show that sexual debut occurs earlier in orphans than non-orphans; by age 12, $30 \%$ of orphan girls are sexually active rising to $85 \%$ by age 18 citing economic need, peer pressure, curiosity and lack of carer supervision as some of the reasons for early sexual activity [12]. The evidence also shows that girls who are orphans are 1.5 times more likely to start sex before the age of 15 than non-orphan girls [13] [14]. By age 19, only $20 \%$ of Ugandan girls are abstaining, $24 \%$ are having premarital sex while $60 \%$ are having sex within marriage [15]. OVC are more vulnerable to early sexual activity because they are more likely not to have adult guidance and also have pressing basic needs compared to majority of their peers [3] [4]. This is true especially for the girls. In Uganda only slightly more than half of all 10 to 14 year old girls live with both parents and $27 \%$ of girls do not live with their mothers [14].

\subsection{School Dropout, Early and Forced Marriages}

Orphaned and vulnerable children drop out of school at a higher rate than non-orphaned children [16] [17]. By age 19, only $12 \%$ of girls are still in school [15]. Younger female OVC aged between 5 and 12 years are at a greater risk of missing out on education as they are in demand as domestic servants for families with young children in urban centres; whereas older female OVC tend to drop out of school and marry early, sometimes as early as the age of 15 years [10]. OVC are more likely to have received no secondary school education and to have started sex early and married, which, in turn were associated with poor reproductive health [1]. The average age girls marry in Uganda is 17.9 and by age 19, only $12 \%$ of girls are still in school [15]. Many girls, particularly those in vulnerable situations, are married off at a young age by carers in exchange for money or material resources [3] [10] [18], and their vulnerability is heightened by the fact that many African societies are patriarchal and some marriages polygamous [12]-[15] [19]. OVC are susceptible to problems such as HIV/AIDS, STIs, marital rape and complications resulting from early pregnancy and childbirth. Blanc's [20] work on power in sexual relationships confirms that sexual partners with marginal power are likely to experience problems and other studies have highlighted the issue of power relations and the difficulty among young married girls in handling their sexual relationships [14] [21] [22].

\subsection{Teenage Pregnancy and Child Motherhood}

Nationally, the teenage pregnancy rate reduced from $31 \%$ in 2005 to $25 \%$ in 2008 but it is still one of the highest in the whole world [7]. 53\% of all teenagers in Uganda are married by the age of 18 and 25\% of adolescent girls have been reported to get pregnant before the age of 19 [6]. Pregnancies among teenage girls have been attributed to maternal orphanhood and parental HIV [1]. Majority of these early marriages and subsequent child motherhood occur among OVC who have dropped out of school, are in situations of conflict or living in poor households [1] [6]. Child motherhood is associated with a higher risk for maternal death and other health risks like high infant mortality and morbidity rates. Girls under 15 years are more likely to die in child birth than 
women in their twenties. An estimated 6000 teenagers die annually from maternal related complications such as obstetric fistula [7]. Child motherhood has also been strongly linked to gender-based violence among teenage girls, the most common form of which is defilement and rape. This has in turn resulted into unwanted pregnancies, unsafe abortions and HIV/AIDS [7] [14].

\subsection{The OVC-HIV/AIDS Nexus}

An estimated $45.6 \%$ of all Ugandan orphans have lost parents to HIV/AIDS [23]. Recent statistics show $0.7 \%$ of all children to be infected with HIV while 20,000 children continue to be infected every year [7]. OVC have been reported to have high proportions of HIV infections, STIs and increased high risk sexual behavior compared to their peers [1] [3]. Local and international research shows that vulnerable children are increasingly using sex as a source of economic exchange and young girls are especially at risk of being solicited for child prostitution which in turn exposes them to HIV/AIDS [24] [25]. Uganda's HIV/AIDS infection rates have continued to increase among 15 - 20 years old who represented over half of new infections in recent years [7] [26]. 25\% of new infections are occurring among young people under the age of 25 and infection rates have also significantly increased among married couples. By the age of 18 - 19, girls are 18 times more likely to have HIV and 8 times more likely to be married. Only 31\% of females aged 15 - 49 and $41.7 \%$ of Ugandans have comprehensive knowledge about HIV/AIDS. Moreover, Uganda is among the 14 African countries with a low condom use rate of less than 20\% [15] [27]. Existing sexual and reproductive health services have been reported to be largely "youth unfriendly" [7] [13] and the majority of health facilities experience continuous stock-outs of medicines and essential supplies like condoms, contraceptives and educative materials [28] [29]. In addition, the majority of OVC (52\%) of vulnerable children live in rural areas compared to the $43 \%$ in urban areas where most services are concentrated [30]; in fact services have been estimated to reach very few OVC in Uganda [8].

\subsection{Synthesis and Critique of OVC Literature}

The literature shows orphanhood and vulnerability as contributors to the descent into poor health outcomes. However there is a dearth of information on related key issues including perceptions of OVC regarding their needs, public perceptions, gender aspects and power issues. There is also little emphasis on the unique sexual and reproductive health needs of boys and young men; data on good practices or successful interventions elsewhere; national child protection systems and responses of duty bearers.

The literature on OVC in sub-Saharan Africa is illuminative and enables us to understand the magnitude, patterns and related outcomes. However it has tended to be narrow, deterministic, pathological, inconsistent and sometimes contradictory. A recurring argument therein is that OVC have poor life trajectories and cannot do anything without the care and support of adults. Whereas this is generally true, it is also narrow because research has not paid attention to the inherent capacities of OVC; neither has it focused on their lived experiences. Furthermore, nearly all of the existing literature presents a curious double-edged pattern: 1) adults are determining categorizing and making damning predictions regarding children - most of these adults are from Western Europe, whose work is situated within Western understandings of childhood and mental health; 2) children's voices are ominously missing. It is this gap in the literature that this study sought to address by researching into the voice and lived experiences of OVC.

This study sought to contribute to developing the minority literature which casts OVC in a different light that is non-pathological. Whereas it was not the intention of this study to deny that many children experience hardship and are in need of support; its central argument is that focusing heavily and narrowly on OVC needs or grim-looking future does not enable an appreciation of local meanings, expressions and responses to the hardships that they experience. This means that there is a very low likelihood of getting a good fit between approaches or interventions and OVC expressed needs. It also presents a very high possibility of distorting local realities and not fully utilising explicit or latent resources and networks.

\section{Methodology}

This was a mixed-methods qualitative study drawing from phenomenology (the study of lived experience) as the predominant approach. It used a combination of different methods including interviews, focus group discussions (FGDs), observation and participatory child-centred methods such as situated interviewing and community 
mapping. The data collection methods used focused on and were intended to enable collection of personal experience and reflections of this experience. Moreover mixed methods helped triangulate study findings and also assure quality. A mix of random and purposive sampling was undertaken to select the 129 study participants. Table 1 presents information pertaining to research participants for this study.

Table 1. Study participants by category, gender and number.

\begin{tabular}{|c|c|c|c|c|}
\hline \multirow{2}{*}{ Data collection method } & \multirow{2}{*}{ Respondent category } & \multicolumn{2}{|c|}{ Gender } & \multirow[b]{2}{*}{ Number } \\
\hline & & Male & Female & \\
\hline & Children and young people & 12 & 13 & 25 \\
\hline \multirow[t]{4}{*}{$\begin{array}{l}\text { Individual interviews } \\
\text { (including participatory methods) }\end{array}$} & Carers & 4 & 8 & 12 \\
\hline & Key informants & 6 & 6 & 12 \\
\hline & Children/ adolescents & 17 & 15 & $4(32)$ \\
\hline & Carers & 4 & 12 & $2(16)$ \\
\hline \multirow[t]{4}{*}{ Focus Group Discussions (FGD) } & Key informants & 5 & 3 & $1(8)$ \\
\hline & Community members & 5 & 3 & $1(8)$ \\
\hline & Mixed (OVC \& carers) & 8 & 8 & $2(16)$ \\
\hline & Total & 61 & 68 & 129 \\
\hline
\end{tabular}

${ }^{*}$ Each FGD had eight (8) participants.

\subsection{Study Context}

This study was conducted in Sheema District which is found in the south western part of Uganda in East Africa. Sheema has a high OVC population of 8296 which, at the time of study, was $39.2 \%$ of the entire district population [31]. Generally, the specific location of the study site was informed by the existing data gaps, logistical convenience, national geopolitical representativeness as well as the presence of OVC programmes.

\subsection{Data Analysis}

Data were primarily analysed manually using the Thematic and Template Analysis (TA) ${ }^{1}$ approach [32]. There was cognizance of the potential methodological tension between allowing children's voices to emerge and using TA's apriori coding because there is a possibility for existing literature and the researcher's experiential knowledge to leave little room for new knowledge to emerge. In order to achieve congruence between the research aims and data analysis a two-phased approach drawing from both TA and grounded theory was undertaken to guide analysis. All interviews and FGDS were recorded and transcribed: those in the local language were translated to English. Data from children's drawings and writings were scanned and typed up for inclusion. In the first phase all data were then read through and the process of organising data for analysis began using the NVivo software [33] [34]. This stage used principles of grounded theory and the NVivo software was helpful in the next phase which used template analysis. In phase two, preliminary analysis was guided by NVivo to develop a template using the key themes emerging from the data. All transcripts were then applied to this master template for analysis. This study was able to achieve its aim of giving voice to study participants while at the same time using available tools to analyse these voices and make sense of their lived experience.

\section{Findings}

Despite being a key theme in the literature, OVC interviewed in this study did not rank their sexual and reproductive health as very bad. In passing OVC mentioned issues of cross-generational sex and the risk of being lured by sugar daddies; however, it was not a recurrent theme as far as their health was concerned. In fact it was in the area of sexual and reproductive health that OVC mentioned their peers as a support system in trying to steer clear ${ }^{1}$ TA website: http://www.hud.ac.uk/hhs/research/template-analysis/. 
of problems. This is shown in one of the FGDs:

G: What do you know about child rights?

Alpha: First of all there are responsibilities. Like doing domestic work, respecting those who take care of you and taking care of them.

Lydia: Advising the fellow youth.

G: About what?

Lydia: How to protect themselves against sugar daddies.

G: How do you do that?

Lydia: We all know we are orphans so we keep reminding each other not to let our guardians down by becoming pregnant or sleeping with sugar daddies. So when one of your friends starts bringing nice things at school which you know she can't afford, you call her as a group and warn her.

G: Really?

Keneva: Yes, that is how we make sure we are responsible. Because if your friend gets pregnant and is chased away from school then you are also to blame to some extent because you didn't advise her.

G: That is very interesting!

Alpha: Yes, I was telling you that for us we don't just think about our rights, we also make sure that we think about our responsibilities and we make sure that we do them. Even boys have sugar mummies but they are not many so it's mainly the girls who suffer.

(FGD with secondary school students aged 13 - 17 years)

The discussion above with OVC in their teenage years shows some key issues. First of all it shows that OVC have agency. They are not passive victims but self-determining actors who leverage on their own resources to create solutions to the problems they face on a daily basis. It also shows the creative ways in which this agency is exercised. As a group OVC are aware of the risks they face as a result of material deprivation for example the lure of sugar daddies or early pregnancy which could result in possible expulsion from school. Therefore as a form of risk management and in full demonstration of agency they do something about it — protect themselves and hold each other accountable. In addition, they are responsible towards their carers-a key feature of the reciprocal nature of the relationships in their lives.

The excerpt also draws our attention to the notion of rights among OVC which is remarkably different from universal assumptions and dominant child rights discourses which posit rights as fixed entitlements and prescribe which actors should be involved in meeting these rights. Rather, OVC's understanding of rights seems experiential, in harmony with their level of need and viewed more as expectations that they kept hoping would be met. In hoping that their rights would be met, still OVC were not very prescriptive but instead highlighted the inextricable link between rights and responsibilities and the fact that their rights were negotiated based on prevailing circumstances. OVC made it very clear that they contribute to the realisation of their rights by supporting those seeking to improve their well-being. Therefore even in their understanding of rights, OVC position themselves not as passive recipients of "rights in implementation" but rather active participants who would want to negotiate these rights based on an understanding of the local context [35].

Furthermore, the FGD excerpt also shows that OVC undertake rational decisions after weighing the impact of these decisions. For example girls [and boys alike] demonstrate awareness of the catastrophic impact that would arise from pregnancy while still in school such as expulsion. OVC have also thought through and learnt from the negative experiences of their lives, such as the fact that members of their families and possibly parents have succumbed to the much dreaded HIV/AIDS which this acts as another deterrent as shown below:

Although it is very tempting I think many girls who are orphans have not been deceived by these sugar daddies. I think it is because they fear that they will catch AIDS or become pregnant.

(Eldard, 14 years)

Some people have control over what happens to them...that is if you listen to advice and also learn from your own situation. For example I know that my parents died from AIDS, so I can avoid being infected by the same.

(Loyda, 13 years)

The majority of OVC spoken to demonstrated high levels of awareness of the risks relating to their sexual and reproductive health. They also showed the way they navigated through these problems. The perceptions, concerns and priorities of OVC are different in so many ways from those of significant adults in their lives, academic scholars trying to study them, policy makers and practitioners trying to intervene. For example on the is- 
sue of early marriage, whereas most child rights activists, health experts and academic scholars strongly oppose it and warn of its related dangers, some OVC looked at it as an escape route to their current troubles and went willingly as shown below:

At least when you get married then you have a family of your own. It is better than getting pregnant. Sometimes girls decide on their own.

(Merabu, 15 years)

The link between culture and sexual health of OVC cannot be overestimated. Within the local traditional culture the place of early marriages is still strong and directly impacts on perceptions of many people, including OVC. In reality and talking to OVC, especially the girls who had dropped out of school, it was very obvious that their sexual and reproductive health status is not good. Despite this however, there are still favourable attitudes towards some of the factors that entrench OVC vulnerability, not only among the community members but also among OVC themselves. As mentioned earlier in this section, OVC showed a reasonably high level of rational thought processes and logical decisions towards some aspects of their sexual and reproductive health. In spite of this however, they were also found to sometimes focus so much on the harsh realities of their current situation and fail to critically foresee the potentially negative impact of their judgment in some situations like having favourable attitudes towards early marriages. For example it is very likely that most OVC whose attitudes are favourable had not thought through the dynamics of the new marital relationship they might find themselves in with a possibly older and stronger partner.

Generally there are structural-cultural, socioeconomic and political factors and some of these include the weak or inexistent child protection systems especially at the community level. Some of the duty bearers demonstrated tolerant attitudes towards some forms of sexual abuse as shown below:

Some of these cases are very simple. For us [police child protection unit] if there is no grievous bodily harm to the victim then we don't take such cases seriously because where do you start?

(Police officer)

These girls of these days...sometimes it is hard to feel sorry for them. They take themselves to these men and then later turn around to say that they were raped...this is usually after they become pregnant and become scared of what to do next

(Health worker)

Such attitudes among are likely to entrench OVC abuse and poor sexual health outcomes. The role of the family in protecting children and young people from harmful sexual behaviour in the emergent socio-cultural, economic and political context was also reported to be weak:

Some of these issues are solved between family members, especially if it is a relative who has done it [sexual abuse]. If it is not a family member sometimes they come and pay bride price then officially marry the girl. Now with such cases you cannot do much.

(Community leader)

This was confirmed by the children as one study participant said:

Okay some girls are raped but it is very difficult to get help because these people [perpetrators] are friends to the leaders or they can pay them. So if the girl is lucky and does not become pregnant she just keeps quiet

(Betesi, 15 years)

As the excerpts above show, despite OVC perceptions and demonstrated agency or resilience, a number of risk factors regarding their sexual and reproductive health are still a major cause of concern. These include poverty, ignorance, weak health and child protection systems, collusive duty bearers and patriarchal values which put male or adult status and privilege above protection of the child.

\section{The Local Health System as It Impacts on OVC Health}

The arrangements in place to respond to the health needs of OVC were reported to be less than ideal. Apart from the very few (only $15 \%$ of study participants) supported by a local NGO, the majority of OVC were totally reliant on the local public health system. Most OVC live within a five kilometre radius of a health facility therefore proximity was not a major problem. In principle all Ugandans are entitled to free healthcare at public health facilities following abolition of user fees in 2001. However, in practice, this is not the case and many health facili- 
ties are unable to respond to the health needs of populations within their areas of jurisdiction. This is as a result of many factors including major stock-out of medicines and sundries; few overworked, underpaid health workers and corruption in the health sector [28] [36]. FGD excerpts below shed further light on this:

G: Tell me about the hospital. What is your experience with the health services?

$\mathrm{L}$ : The health centre is about 2 miles from where I live so we can get there easily. But...the queues are long.

$\boldsymbol{E}:$ The hospital is near but some of those nurses are not good. They see you almost dying and leave you there. If you don't give them money or bring them something they will first attend to others.

M: Some of us don't even bother going there because we know what we shall find. You would rather get herbs or even just stay home and sleep. Then for sexual health, most of the young people fear to be seen at the clinic because they [health workers] will report them to their guardians or talk about them that they came to get condoms or pills...so we don't go.

(FGD with out-of-school youth aged 14-17 years)

According to the Ministry of Health [36], frustrations with poor service delivery in Uganda's health system is not only experienced by OVC but the majority of the population. The country is grappling with issues of low access to and utilisation of health services as a result of many factors including limited funding, low human resources for health, poor infrastructure, and incessant stock out of medical supplies among others. Therefore in light of the above, the local health system is too stretched and lacks the capacity to respond to the unique health concerns of OVC by providing adolescent-centred health services including bespoke sexual and reproductive health services. The current national strategic plan for OVC notes that " the number of facilities providing child-friendly and adolescent reproductive health remains limited... and data to track improvement in health services specifically for OVC is not readily available” [7].

\section{Discussion}

The model of childhood that continues to exist in many developing countries like Uganda is one of passive recipients of adults' decision making. Usually the children and young people at most risk of significant sexual and reproductive health problems are already vulnerable and many of the perpetrators reported to be trusted adults in their lives. Girls face disproportionate vulnerability and gender should be integral as a guiding principle in OVC interventions; it would be useful to utilise a feminist framework in understanding the experiences of children and young people, particularly girls.

In largely patriarchal societies that are also short on professionals with expertise in child-centred approaches, questions remain on the research design, methods and tools used in conducting studies with children, particularly on sensitive topics like sexuality. Furthermore, the way some "educational" messages were packaged by practitioners leave some room for improvement. This is particularly in relation to messages or teachings given to children on sexuality. Contrary to SRH knowledge among teenagers, what was found in many children's minds was a deficit approach to understanding and managing sexual and reproductive health issues. The approach to sexuality was generally alarmist and children seemed to have understood the need to keep away from sex-related activities more out of fear than a healthy, balanced understanding of its pros and cons. Below are two definitions of sex (Figure 1 and Figure 2).

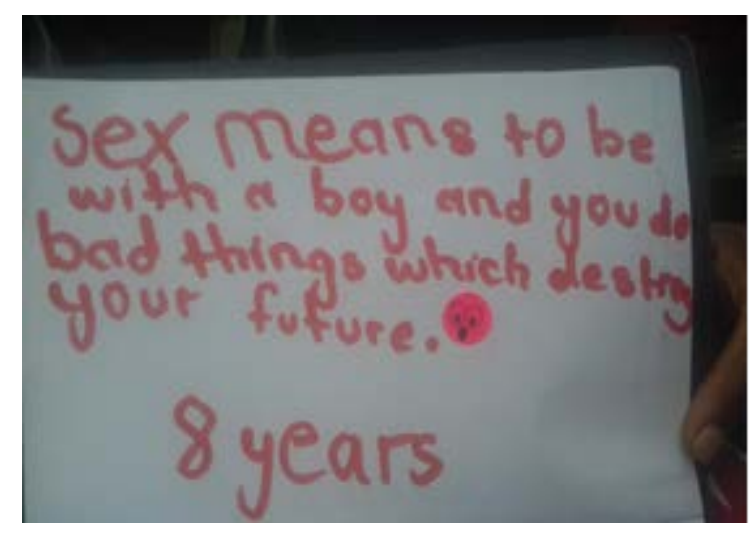

Figure 1. Children’s conceptualisation of sex. 


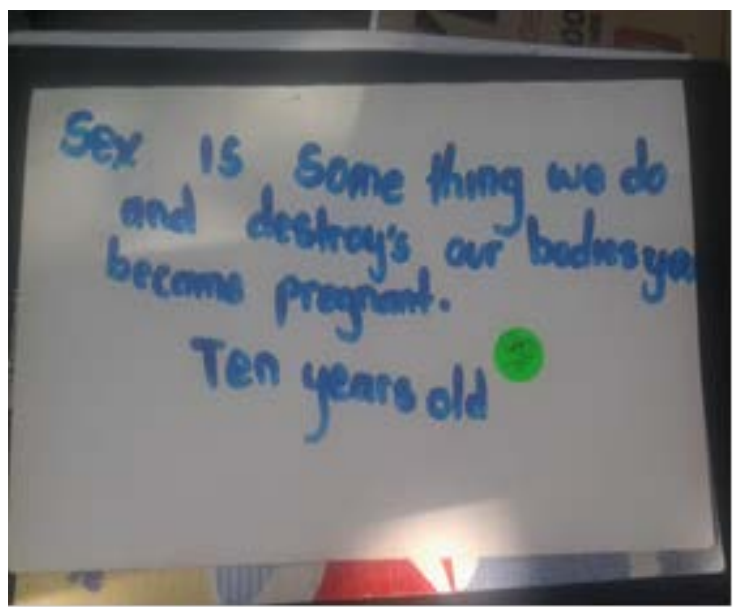

Figure 2. Children's conceptualisation of sex.

Whereas the above understanding has elements of truth (e.g. sex does lead to pregnancy), it is not entirely a balanced or healthy opinion and is skewed to the negative. With such fearsome attitudes to sexuality it might be possible that children and young people find problems (both now and later) in their relationships with theopposite sex. In fact this could lead to future problems in their sexual and reproductive health, thereby undermining policy and programme efforts.

The notion of children and young people's "voice" is generally missing in most of the studies that have been undertaken. Child-centred approaches and related methodology need to be integrated in research and other interventions for OVC, and this includes giving them 'voice' regarding their own reproductive and sexual health.

\subsection{The Shifting Role of Adults}

The findings of this study show a high level of incongruence between how sexual health is understood by adults and how it is experienced by the children young people and young people themselves. This discrepancy becomes ever more important when dealing with youth with complex circumstances like OVC who have not trodden a relatively "normal" pathway. As mentioned before many OVC have agency and have devised ways of protecting themselves against poor sexual and reproductive health outcomes. They have also made, and continue making, tremendous contributions to not only their households but also the societies of which they are part. An understanding and appreciation of the unique position and contributions of OVC should therefore usher in new ways of thinking about and engaging with them. First of all, adults viewing children and young people from a patriarchal lens need to acknowledge that they do not know everything about them. They need to understand, embrace and sustain the initiatives and contributions of OVC to society. This also changes the relational interface between these two groups; adults shift from seeing themselves as "experts" to becoming more of facilitators, confidants, guardians, partners and learners in issues regarding OVC. The shifting of adult roles in relation to OVC is not simplistic but an on-going iterative process that will require a full appreciation of the related ethical, political and cultural tensions involved therein. It will also require employing child and adolescent-centred methodologies [37] to elicit the most from the OVC in their new recognised position as active contributors to society.

\subsection{A Child and Adolescent-Centred Lens}

Child and adolescent-centred approaches need to be adopted in research, policy and practice; the underlying social constructions of childhood and their resulting opportunities or limitations should also be understood. Parents, carers and other significant adults in the lives of children and young people are part of the solution and should be supported. There are protective factors within many Ugandan families and communities that can and must be harnessed to protect children and young people.

Service delivery and health system issues, including capacity-building at key points such as health facilities and schools, should be looked into. There is need for provision of services tailored to unique reproductive and sexual health needs of different OVC categories. This stratification based on clusters like age, marital status, 
area of residence, sexual activity or orientation requires avoidance of the one-size-fits-all approach, diversity in menu of services on offer and inclusion of hard-to-reach people or areas. The need to support civil society and other actors in their effort to broaden the scope of available services is also immense. The need for further multi-targeted educational campaigns for all relevant stakeholders cannot be underestimated. Learning from the relatively weak implementation of existing policy, legislative action and stronger child protection systems will need prioritisation and adequate resources.

\section{Conclusion}

This study confirms the poor status of OVC sexual and reproductive health. However, the majority of existing OVC representations, including those related to their sexual and reproductive health, are adult constructs not necessarily subscribed to by OVC themselves. Acknowledging their difficult circumstances, most OVC have devised creative ways of addressing challenges associated with their sexual and reproductive health which need to be identified, celebrated and consolidated by those seeking to improve their outcomes. Essentially what is required is a multi-pronged approach which positions children's lived experiences, voices and priorities at the heart of all interventions. Different stakeholders need to act on the need for an integrated child and adolescent-centred approach to the sexual and reproductive health of orphans and vulnerable children.

\section{References}

[1] Birdthistle, I., Floyd, S., Nyagadza, A., Mudziwapasi, N., Gregson, S. and Glynn, J.R. (2009) Is Education the Link Between Orphanhood and HIV/HSV-2 Risk among Female Adolescents in Urban Zimbabwe? Social Science \& Medicine, 68, 1810-1818. http://dx.doi.org/10.1016/j.socscimed.2009.02.035

[2] Gregson, S., Nyamukapa, C.A., Garnett, G.P., Wambe, M., Lewis, J.J.C. and Mason, P.R. (2005) HIV Infection and Reproductive Health in Teenage Women Orphaned and Made Vulnerable by AIDS in Zimbabwe. AIDS Care, 17, 785794. http://dx.doi.org/10.1080/09540120500258029

[3] Birdthistle, I.J., Floyd, S., Machingura, A., Mudziwapesi, N., Gregson, S. and Glynn, J.R. (2008) From Affected to Infected? Orphanhood and HIV Risk among Female Adolescents in Urban Zimbabwe. AIDS Care, 22, 759-766.

[4] Andrews, G., Skinner, D. and Zuma, K. (2006) Epidemiology of Health and Vulnerability among Children Orphaned and Made Vulnerable by HIV/AIDS in Sub-Saharan Africa. AIDS Care, 18, 269-276. http://dx.doi.org/10.1080/09540120500471861

[5] Skinner, D., Tsheko, N., Mtero-Munyati, S., Segwabe, M., Chibatamoto, P., Mfecane, S., Chandiwana, B., Nkomo, N., Tlou, S. and Chitiyo, G. (2006) Towards a Definition of Orphaned and Vulnerable Children. AIDS and Behaviour, 10, 619-626. http://dx.doi.org/10.1007/s10461-006-9086-6

[6] UBOS, Uganda Bureau of Statistics (2006) Uganda National Household Survey 2005/06. Uganda Bureau of Statistics, Kampala.

[7] Uganda Ministry of Gender, Labour and Social Development (2004) National Orphans and Other Vulnerable Children Policy (NOP).

[8] Kalibala, S. and Elson, L. (2010) Situation Analysis of Vulnerable Children in Uganda. Population Council, New York.

[9] UNICEF and The Government of Uganda (2005) Suffering in Silence: A Study of Sexual and Gender Based Violence (SGBV) in Pabbo Camp, Gulu District, Northern Uganda.

[10] Oleke, C., Blystad, A., et al. (2006) The Varying Vulnerability of African Orphans: The Case of Langi, Northern Uganda. Childhood, 13, 267-284.

[11] Households: Caring for Their Future Today.

[12] Sharpe, U., Ssentongo, R. and Ssenyonga, A. (1993) Orphans Sexual Behaviour in Masaka Diocese, Uganda. 9th International Conference on AIDS, Berlin, 6-11 June 1993.

[13] Hulton, A., Cullen, R. and Khalokho, S.W. (2000) Perceptions of the Risks of Sexual Activity and Their Consequences among Ugandan Adolescents. Studies in Family Planning, 31, 35-46. http://dx.doi.org/10.1111/j.1728-4465.2000.00035.x

[14] Neema, S., Musisi, N. and Kibombo R (2004) Adolescent and Reproductive Health in Uganda: A Synthesis of Research Evidence. Occasional Report, No. 14, The Alan Guttmacher Institute, New York.

[15] Watson, C. (2006) Uganda: HIV/AIDS and the Age Factor. Straight Talk Foundation, Kampala.

[16] Boler, T. and Caroll, K. (2003) Addressing the Educational Needs of Orphans and Vulnerable Children. Action Aid 
and Save the Children Fund, London.

[17] Sewankambo, N.K., Gray, R.H., Ahmad, S., Serwadda, D., Wabwire-Mangen, F., Nalugoda, F., Kiwanuka, N., Lutalo, T., Kigozi, G., Li, C., Meehan, M.P., Brahmbatt, H. and Wawer, M.J. (2000) Mortality Associated with HIV Infection in Rural Rakai District, Uganda. AIDS, 14, 2391-2400.

[18] Foster, G. and Williamson, J. (2000) A Review of Current Literature of the Impact of HIV/AIDS on Children in SubSaharan Africa. AIDS, 14, S275-S284.

[19] WHO (2010) Social Determinants of Sexual and Reproductive Health: Informing Future Research and Programme Implementation.

[20] Blanc, A.K. (2001) The Effect of Power in Sexual Relationships on Sexual and Reproductive Health. An Examination of the Evidence.

[21] Straight Talk Foundation (2008) Annual Report: Kampala.

[22] Koenig, M.A., Lutalo, T., Zhao, F., Nalugoda, F., Wabwire-Mangen, F., Kiwanuka, N., Wagman, J., Serwadda, D., Wawer, M. and Gray, R. (2003) Domestic Violence in Rural Uganda: Evidence from a Community-Based Study. Bulletin of the World Health Organization, 81, 53.

[23] UNAIDS (2010) Report on Global AIDS Pandemic.

[24] Jones, A. and Trottman-Jemmot, E. (2009) Devastated Childhoods: Study of Perceptions to, and Opinions on Child Sexual Abuse in the Eastern Caribbean. Unpublished Document.

[25] De Berry, J. (2004) The Sexual Vulnerability of Adolescents Girls during Civil War in Teso, Uganda. In: Boyden, J. and De Berry, J., Eds., Children and Youth on the Frontline: Ethnography, Armed Conflict and Displacement, Berghahn, New York, 45-62.

[26] UHNS Uganda National Health Survey (2010) Kampala: Uganda Bureau of Statistics.

[27] UNAIDS (2010) Report on Global AIDS Pandemic.

[28] MHSDMU: Medicines and Health Service Delivery Monitoring Unit (2011) Annual Report. Kampala.

[29] Uganda AIDS Commision (2010) Country Progress Report

[30] Walakira, E.J., Ochen, E.A. and Mugumya, F. (2007) HIV/AIDS Services and Gaps Analysis for Northern and Eastern Uganda.

[31] (2011) Sheema District Local Government Report.

[32] King, N. (1998) Template Analysis. In: Symon, G. and Cassell, C., Eds., Qualitative Methods and Analysis in Organizational Research, Sage, London.

[33] Bazely, P. (2007) Qualitative Data Analysis with NVivo. 2nd Edition, Sage, London.

[34] Gibbs, G.R. (2002) Qualitative Data Analysis: Explorations with NVivo. Open University Press, Buckingham.

[35] Jones, A. (2009) Social Marginalisation and Children’s Rights: HIV Infected Children in the Republic of Trinidad and Tobago. Health and Social Work. Special Issue on Health and Inequality. NASW Press, Washington DC.

[36] Ministry of Health (2010) Health Sector Strategic Plan III 2010/11-2015/15. Kampala.

[37] Alderson, P. (1995) Listening to Children: Children, Ethics and Social Research. Barnados, Illford. 
Scientific Research Publishing (SCIRP) is one of the largest Open Access journal publishers. It is currently publishing more than 200 open access, online, peer-reviewed journals covering a wide range of academic disciplines. SCIRP serves the worldwide academic communities and contributes to the progress and application of science with its publication.

Other selected journals from SCIRP are listed as below. Submit your manuscript to us via either submit@scirp.org or Online Submission Portal.
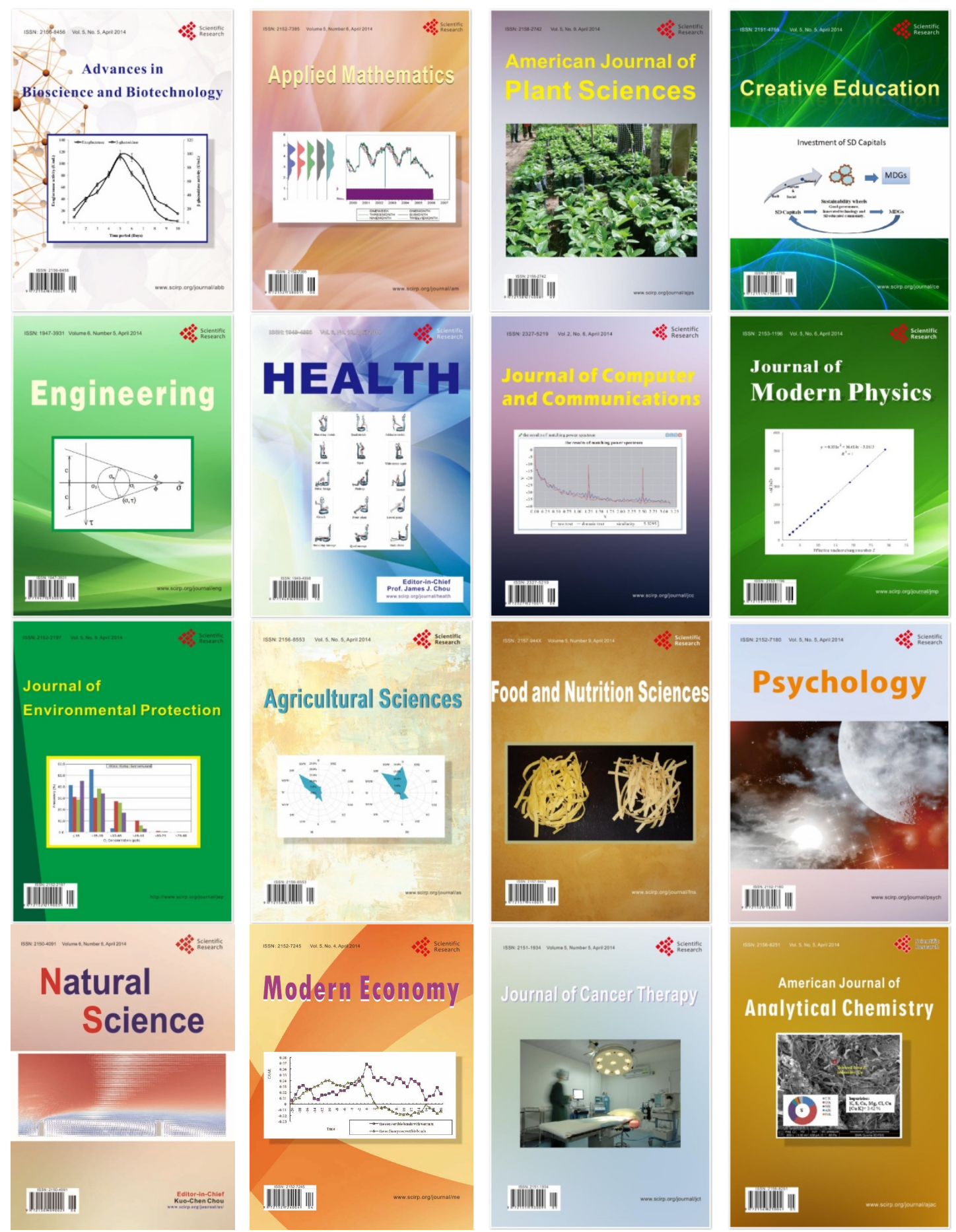